\title{
RED CROSS HELPS FIGHT DISEASE
}

In the fight against disease Red Cross volunteers, both junior and adult, are front-line shock troops in many parts of the world. Here are some of the ways they help to stem, and in some cases eliminate, once dreaded epidemics.

In the Estonian Republic of the USSR, polio is a thing of the past, thanks in part to the intense activity of Red Cross Juniors who make up the striking total of 92 per cent of the school population.

The Juniors played an important role in an anti-polio campaign organised by medical authorities. They helped convince the population of the need for mass vaccination, and distributed oral vaccines to all those under 20 .

Threatened by a cholera outbreak in August, 1966, Iraq relied heavily on trained Red Crescent volunteers in thwarting what might have been a grave epidemic.

Armed with anti-cholera vaccines given by the LSSR Alliance of Red Cross'Red Crescent Societies, a dozen four-man teams worked 12 hours a day for a fortnight in Baghdad and its outshirts. They inoculated 15,500 men, women and children-and the disease was efiectively held at bay.

The Niger Red Cross, youngest member of the League of Red Cross Societies, is active in its country's fight against malaria. Volunteers make regular visits to villages in the interior, bringing precious anti-malaria medicaments and teaching the population elementary rules aimed at preventing the disease.

Parasites which pass from sheep to dogs to humans cause hydatids-cysts which can be fatal if they are not caught in time.

In New Zealand, one of the world's major sheep-raising countries, Junior Red Cross took up the fight against hydatids as a 
health education project, in co-operation with government health serrices and agricultural authorities.

Pilot teams were charged with getting all the facts concerning the pest and how to eradicate it and passing them on to fellow Juniors in their school. They, in their turn, were asked to spread this knowledge to reighbouring schools and adult organisations in their own and nearby communities.

"If everyone implements what you teach, this thief, robber and killer will be eradicated in a short time", was the motto of these young Red Cross members.

In many countries, such as Rumania, Red Cross volunteers participate actively alongside health authorities in national smallpox eradication campaigns.

- They organise "doctor meets the public" sessions, lectures and forums to educate the public on the need for vaccination;

- They help with door to door canvassing to enlist persons needing vaccination, help health authorities draw up lists of those requiring vaccination and distribute reminder notices;

- When the vaccination campaign reaches a district, Red Cross volunteers "mobilise" those needing vaccinations by groups of ten, and guarantee that they attend clinics.

Peru: Young Red Cross volunteers are bringing new hope for better health and more useful lives to families living in the depressed suburbs of Lima, Peru.

What are these suburbs like? Some have mushroomed on a dried-up river bed. Whole families live there, amongst rubbish heaps of all kinds, parents and children crowded in one room, sometimes with a few chickens and rabbits. It is to the huge task of improving such conditions that the Peruvian JRC decided, in 1964, to devote its energies.

First, the Red Cross asked teacher-sponsors and first-aiders to undertake a social survey to enable it to select families on the basis of such criteria as income, number of children, food habits, health status, etc. Would the families be interested in the Red Cross project and give it their active support?

This brought out the most acute needs of the residents: learning to read and write, to sew, to make small pieces of furniture, to 


\section{IN THE RED CROSS WORLD}

improve their diet, etc. The Red Cross organised courses to meet these demands-and more than 2,000 people are now attending literacy courses and learning how to draw up a well balanced menu, how to wield a hammer and saw, how to use needle and thread...

Learning is but one aim. The other is to use this learning to improve local conditions. So the Red Cross is also trying to show families how to put this new krowledge into practice.

Through a programme of home risits, families are taught how to wash with a minimum amount of water, how to prepare nutritive meals with foods little known to Perurian families, yet rich in proteins and which can easily supplement traditional dishes; how to make a bed with packing cases.

Many young people living in these fringe areas have joined the Red Cross and formed JRC units. These include both youngsters who are still in the primary school, and others who are already working. They learn first aid and have made it one of their responsibilities to assist in emergencies. They now take an active part in efforts to improve health and living conditions in their own community. 